\title{
Preparation of ultrafine grained copper nanoparticles via immersion deposit method
}

\author{
Fatemeh Abbasi-Kesbi ${ }^{1}$. Ali Mohammad Rashidi ${ }^{1}$ Bandar Astinchap ${ }^{2}$
}

Received: 15 May 2017 / Accepted: 22 December 2017 / Published online: 12 March 2018

๑) Springer-Verlag GmbH Germany, part of Springer Nature 2018

\begin{abstract}
Today, the exploration about synthesis of nanoparticles is much of interest to materials scientists. In this work, copper nanoparticles have been successfully synthesized by immersion deposit method in the absence of any stabilizing and reducing agents. Copper (II) sulfate pentahydrate as precursor salt and distilled water and Ethylene glycol as solvents were used. The copper nanoparticles were deposited on plates of low carbon steel. The effects of copper sulfate concentrations and solvent type were investigated. X-ray diffraction, scanning electron microscopy and UV-Visible spectroscopy were taken to investigate the crystallite size, crystal structure, and morphology and size distribution and the growth process of the nanoparticles of obtained $\mathrm{Cu}$ particles. The results indicated that the immersion deposit method is a particularly suitable method for synthesis of semispherical copper nanoparticles with the crystallites size in the range of $\sim 22$ to $37 \mathrm{~nm}$. By increasing the molar concentration of copper sulfate in distilled water solvent from 0.04 to $0.2 \mathrm{M}$, the average particles size is increased from 57 to $81 \mathrm{~nm}$. The better size distribution of $\mathrm{Cu}$ nanoparticles was achieved using a lower concentration of copper sulfate. By increasing the molar concentration of copper sulfate in water solvent from 0.04 to 0.2, the location of the SPR peak has shifted from 600 to $630 \mathrm{~nm}$. The finer $\mathrm{Cu}$ nanoparticles were formed using ethylene glycol instead water as a solvent. Also, the agglomeration and overlapping of nanoparticles in ethylene glycol were less than that of water solvent.
\end{abstract}

Keywords Electroless plating $\cdot$ Immersion deposit $\cdot \mathrm{Cu}$ nanoparticles $\cdot$ Solvent $\cdot$ Distilled water $\cdot$ Ethylene glycol

\section{Introduction}

Recently, metallic nanoparticles (NPs) with dimensions less than $100 \mathrm{~nm}$ have been lots of attention in the scientific community and industry. Because NPs show that unique chemical and physical properties attributed to their relatively small size and high surface area-to-volume ratio. For example, metallic NPs were found to have 7-50 times less toxic effect to mammalian cells than their corresponding ionic forms (Chatterjee et al. 2014). Among metallic NPs, copper nanoparticles have been considerable attention due to antibacterial capacitance (Chatterjee et al. 2014; Argueta-Figueroa et al. 2014; Usman 2013; EmanAlzahrani and Ahmed 2016),

Ali Mohammad Rashidi

rashidi1347@ razi.ac.ir

1 Department of Materials Engineering, Faculty of Engineering, Razi University, P.O. Box 67149-67346, Kermanshah, Iran

2 Physic Department, Faculty of Science, University of Kurdistan, Sanandaj 66177-15175, Iran high catalytic activity and selectivity (EmanAlzahrani and Ahmed 2016; Sherazi et al. 2014), excellent electrical conductivity (Magdassi et al. 2010; Lee et al. 2008) and a remarkable increment in heat transfer of fluids (Eastman et al. 2001; Garg et al. 2008). Also, Cu NPs are low cost in production compared to precision metal such as silver, while its conductivity is only 6\% less than that of Ag (Magdassi et al. 2010).

Due to excellent electrical conductivity, $\mathrm{Cu}$ NPs can be used to make conductive pastes for the formation of thick film conductors such as electrodes or conductive patterns in printed circuit boards, hybrid integrated circuit and metallization of multilayer ceramic capacitor in the electronic industries (Lee et al. 2008). It has been found that $\mathrm{Cu}$ NPs exhibit a wide spectrum of antimicrobial activity against different species of microorganisms (Chatterjee et al. 2014; Argueta-Figueroa et al. 2014; Usman 2013; EmanAlzahrani and Ahmed 2016). EmanAlzahrani and Ahmed (2016) successfully constructed a non-enzymatic sensor for $\mathrm{H} 2 \mathrm{O} 2$ determination based on $\mathrm{Cu}$ NPs with high catalytic activity which could be used in biomedical applications. According 
to the work of Eastman et al. (Eastman et al. 2001), thermal conductivity of ethylene glycol can be increased by up to $40 \%$ through the dispersion of $0.3 \mathrm{vol} \% \mathrm{Cu}$ NPs of mean diameter $<10 \mathrm{~nm}$. In summary, it can be concluded that the $\mathrm{Cu}$ NPs present a wide range of potential applications in various fields such as antibiofouling agents, electronic devices, optical sensor, catalysts, solar/photovoltaic energy conversion and industrial cooling and heating.

Since the 1990s, scientists have focused on the development of chemical and physical methods to synthesize of $\mathrm{Cu}$ NPs (Magdassi et al. 2010). Some of these methods include the metal vapor synthesis (Vitulli et al. 2002), chemical reduction in solution (Huang et al. 1997; Khan et al. 2016; Leong 2016; Umer et al. 2014), sonochemical techniques (Kumar et al. 2001; Dhas et al. 1998), hydrothermal processes (Betancourt-Galindo et al. 2014), microemulsion methods (Qi et al. 1997), thermal reduction (Dhas et al. 1998), electron beam irradiation methods (Zhou et al. 2008), polyol synthesis (Park et al. 2007 Jul 15), electrochemical reduction (Hashemipour et al. 2011) and Sonoelectrochemical synthesis (Sáez and Mason 2009). Most of methods tend to be expensive, environmental incompatibility and time consuming. Among the chemical methods, electroless (autocatalytic) plating is easy, cost effective and available equipment (Porter et al. 2002). Electroless plating refers to the autocatalytic or chemical reduction of aqueous metal ions plated to a base substrate (metals, ceramics or plastics) at room temperature, by just immersing the substrate into an electrolyte solution. This method involves the presence of a chemical reducing agent in solution to reduce metallic ions to the metal state in the absence of an external source of electric current. Unlike electroplating, it is not necessary to pass an electric current through the solution to form a deposit. Power supplies, electrical contacts, and the other apparatus necessary for electroplating are not required (Barker 1981; Henry 2001; Schlesinger and Paunovic 2010; Ohno 1991; Srinivasan et al. 1988). This method can be utilized in various uses due to its specific properties, although thickness is uniform even on complex-shaped parts and small cavities. Also, the deposit has low porosity as well as unique chemical, mechanical, and magnetic properties, for instance, corrosion and wear resistance. On the other hand, electroless plating solutions have limited bath life because the reduction of reaction products accumulated in the solution and, finally, the salt content will be expensive. It should be noted that the short lifetime of the baths is a serious limitation from both cost and environmental views. So, sometimes accumulated impurities shorten the solution life (Yli-Pentti 2014; Sudagar et al. 2013). The process relies on the presence of a reducing agent (electron donors) in aqueous solutions, which reacts with the metal ions (electron acceptors) to deposit metal. In this method, there are many parameters such as temperature, reaction time, precursor and reducing agent type and concentration, additive type and even mixing affecting on nucleation, growth and agglomeration phenomena and consequently the particle size distribution (Barker 1981; Henry 2001; Schlesinger and Paunovic 2010; Ohno 1991; Srinivasan et al. 1988). When an iron alloy such as steel is immersed in a copper sulfate solution, the iron dissolves while the copper is plated out onto its surface. This is called an immersion deposit and is used commercially for the production of copper coatings on base metals or suitably activated non-metallic surfaces (Barker 1981). The immersion deposit of copper formed on steel from simple acidic copper solutions is non-adherent and spongy (Camacho-Flores et al. 2015). On the other hand, deposition of copper powder requires spongy deposition (Hashemipour et al. 2011). Accordingly, electroless plating of copper via immersion of steel substrate in a copper sulfate solution is appropriate method for the fabrication of nanoparticle in a single process (Yagi et al. 2009). In this method, the deposition of metal starts at specific activation sites on the surface and continues on these points only. As deposition progresses, islands are formed around these nucleation sites. The islands grow in size until they merge and a continuous film results (Porter et al. 2002). In fact, electroless plating involves nucleation and growth during the deposing process, growth is enhanced over nucleation in smooth cathodes but the converse is true for powder production where each nucleus is a powder particle. Therefore, nanoparticles can be achieved by controlling of process parameters so that it leads to an increase in the nucleation rate with respect to the growth rate (Xue et al. 2006).

Unfortunately, there is a lack of understanding of the process parameters effects on the crystallite size, morphology of particles and agglomeration phenomena in the synthesis of the copper NPs via immersion plating method. Therefore, to overcome these deficiencies, the authors decided to synthesize the copper NPs via electroless plating, namely, immersion deposit of copper formed on steel and study the effect of the some process parameters (concentrations and solvent type) on the morphology and size of the obtained nanoparticles.

It should be noted that in most of chemical methods used by other researchers, the copper NPs formed by homogeneous nucleation and the synthesis process are the complicated batch, requiring specific stabilizing and reducing agents and expensive equipment, producing small amount of nanoparticles as well as environmental incompatibility (Umer et al. 2014). In contrast, in the immersion deposit method, the copper NPs are formed by heterogeneous nucleation without the use of any chemical stabilizer and protector agents, and the synthesis process is simple, high efficiency, high throughput, and potential to easily become a continuous process (Porter et al. 2002). 


\section{Experimental}

\section{Materials}

Copper (II) sulfate pentahydrate $\left(\mathrm{CuSO}_{4} \cdot 5 \mathrm{H} 2 \mathrm{O}\right)$, Ethanol and Ethylene glycol were purchased from Merck Company and used as received without further purification. Also, low carbon steel $(0.08 \mathrm{wt} \% \mathrm{C})$ plates $\left(12 \times 16 \mathrm{~cm}^{2}\right)$ and double distilled water were used.

\section{Synthesis method}

According to the procedure described (Srinivasan et al. 1988), in the first step, different homogeneous solutions of $\mathrm{CuSO}_{4}$ with concentrations of $0.04,0.12$ and $0.2 \mathrm{M}$ were prepared in distilled water. Mild steel plates were mechanically finished in order to achieve to a mirror finish. The samples were rinsed with acetone and distilled water and then immersed in the copper sulfate solution at room temperature $\left(25^{\circ} \mathrm{C}\right)$. After short over time, a non-adherent layer of metallic copper particles was formed onto its surface. The entire substrate was removed from the solution and rinsed with double distilled water for two times. The copper on the substrate was separated with a polymer blade and kept in the preservative solvent of ethanol to prevent oxidation. Finally, the effect of solvent type was tested at room temperature using 0.12 and $0.2 \mathrm{M}$ ethylene glycol as solvent instead of 0.12 and $0.2 \mathrm{M}$ double distilled water.

\section{Characterization techniques}

The characterization of nanometric scale structures is carried out by different techniques such as transmission electron microscopy (TEM), the scanning electron microscope (SEM), dynamic light scattering (DLS), X-ray scattering at small angles (SAXS), X-ray diffraction (XRD) and ultraviolet-visible (UV-Vis) spectroscopy (Yagi et al. 2009). The SEM is an instrument that allows the observation of the shape and size of the Cu NPs. The XRD is a scientific technique primarily used for phase identification of a crystalline material and can provide information on unit cell dimensions as well as nanoparticle size (Cullity 1978). UV-Visible absorbance spectroscopy is a very useful technique for studying metal nanoparticles because the peak position and shapes vary when changing particle size (Shikha et al. 2015).

Accordingly, in this work, the $\mathrm{Cu}$ nanoparticles have been characterized by the SEM, UV-Vis and XRD. The SEM characterization was carried out using an EM3200 electron microscope. The average diameters and size distributions of the copper particles were obtained from the enlarged SEM photographs.

To record absorption spectra of NPs, a UV-Vis spectrophotometer (jasco v-630) in a $1 \mathrm{~cm}$ optical path quartz cuvette over a $200-800 \mathrm{~nm}$ range was used to preliminary estimation of $\mathrm{Cu}$ NPs synthesis. The X-ray diffraction studies were carried out using an APD 2000 X-ray diffractometer operated at $40 \mathrm{kV}$ and $30 \mathrm{~mA}$ with $\mathrm{CuK} \alpha$ radiation

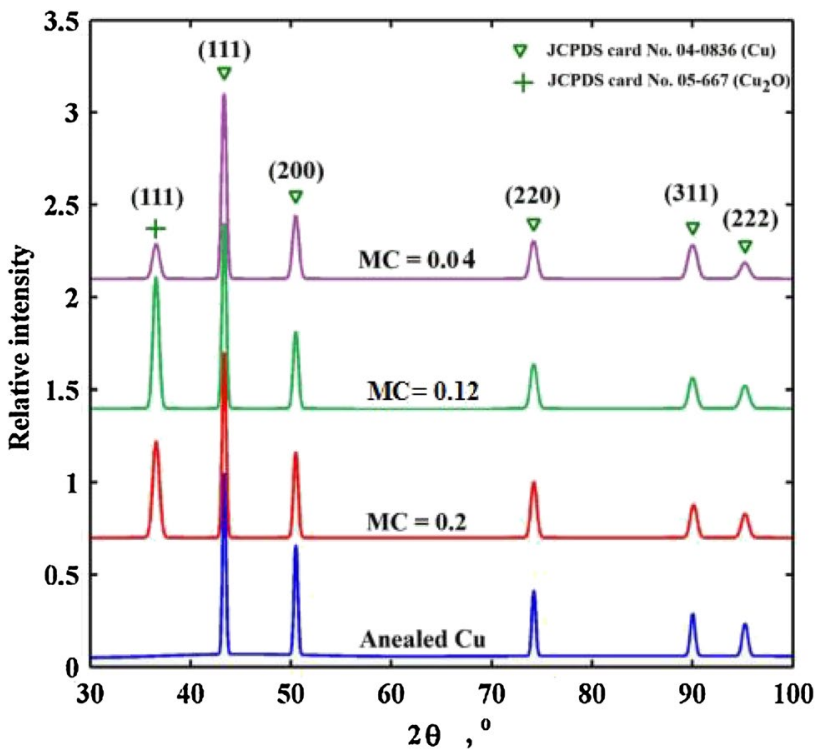

Fig. 1 XRD Pattern of nanoparticles prepared from water solvent with different molar concentration (MC) of $\mathrm{CuSO}_{4}$

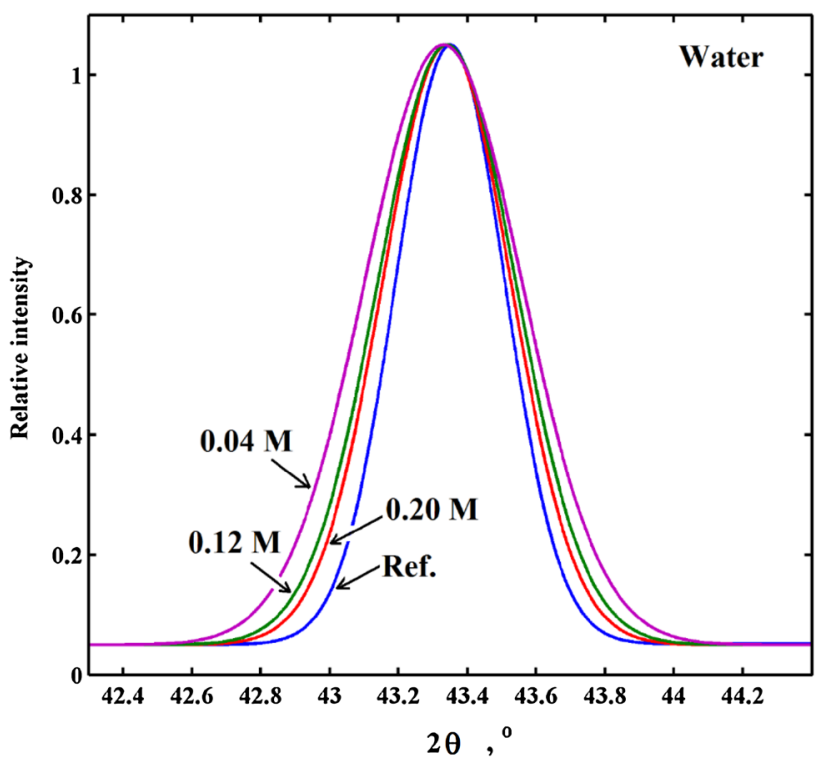

Fig. 2 Comparison of normalized (111) reflection peaks of ref. sample and nanoparticles of $\mathrm{Cu}$ prepared from water solvent with different molar concentration of $\mathrm{CuSO}_{4}$

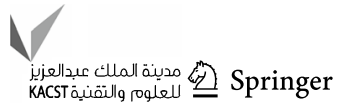




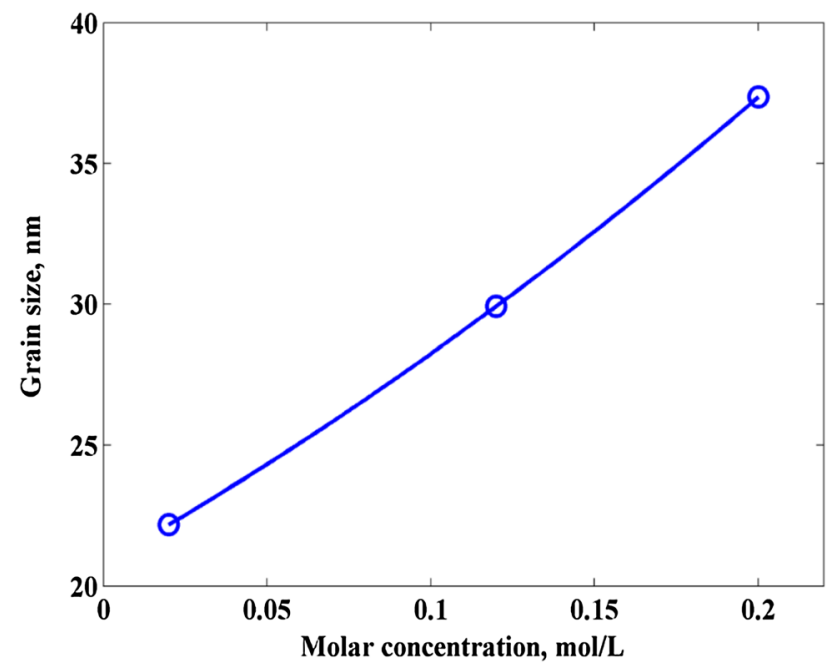

Fig. 3 Variation of crystallite size of copper deposits as a function of $\mathrm{CuSO}_{4}$ concentration in water solvent $(\lambda=1.54187 \AA)$. A suitable quantity of Cu NPs was prepared by drying. The XRD patterns were recorded in a $2 \theta$ range of 20o-80o with a scanning step of 0.05 ". The average crystallites size of the $\mathrm{Cu}$ nanoparticles was calculated from XRD patterns via Scherrer equation:

$d=\frac{k \lambda}{\beta \cos \left(\theta_{o}\right)}$

where the value of $d$ represents the size of the crystallites, and $\lambda, \theta_{0}$ and $\beta$ are the wavelength of radiation, the Bragg diffraction angle and the intrinsic (true) profile full width at half maximum intensity (FWHM), respectively. The $\beta$ parameter was calculated using the Gaussian-Gaussian relation (Tjong and Chen 2004):

$\beta^{2}=\beta_{\exp }^{2}-\beta_{\text {ins }}^{2}$
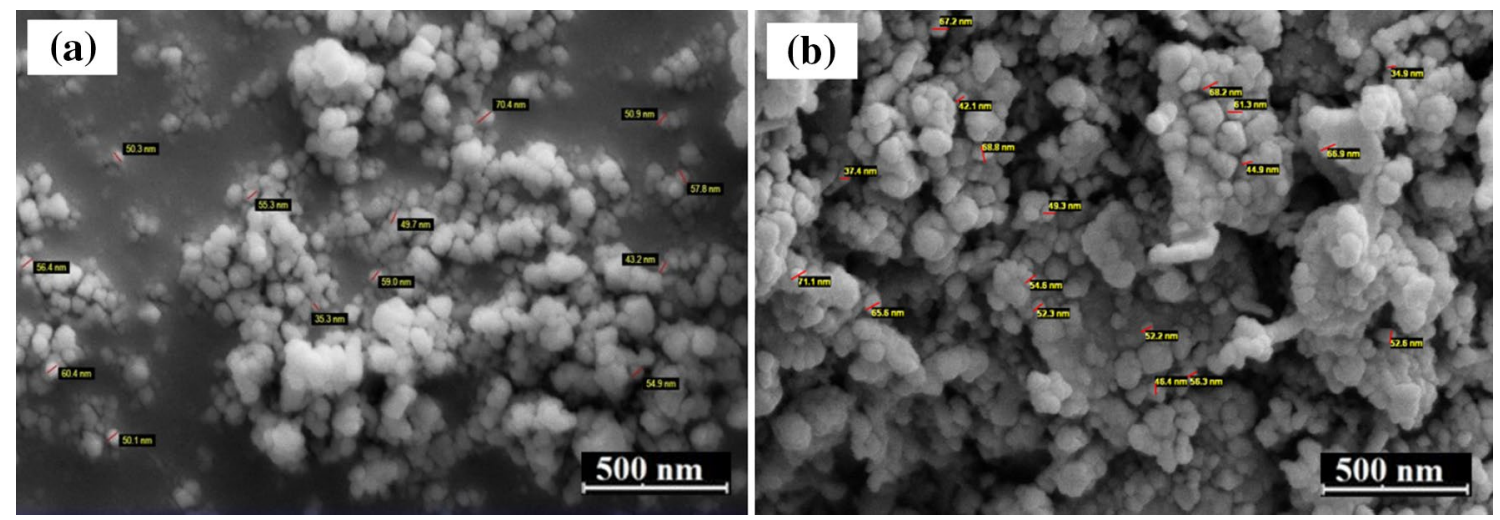

Fig. 4 SEM images of nanoparticles of $\mathrm{Cu}$ prepared from water solvent with $\mathbf{a} 0.04$ and $\mathbf{b} 0.20$ molar concentration of $\mathrm{CuSO}_{4}$
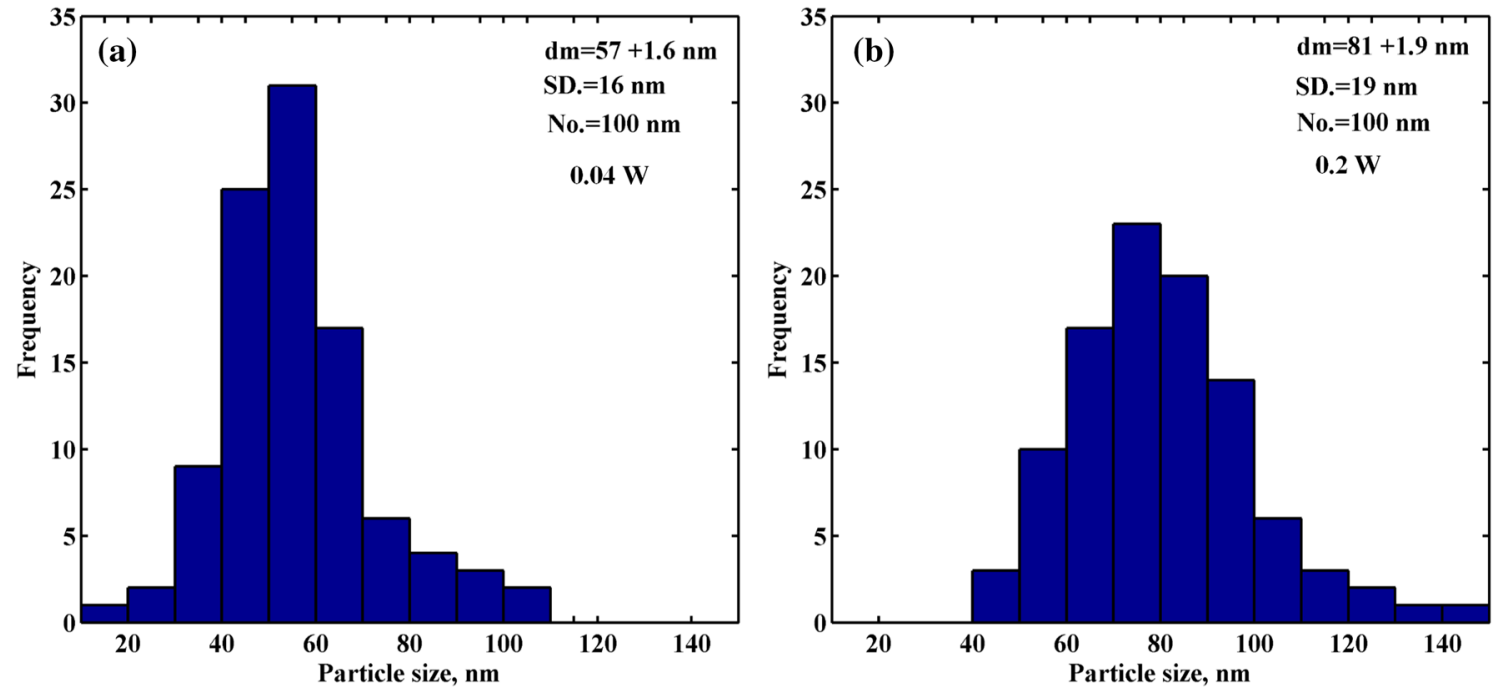

Fig. 5 Size histograms of $\mathrm{Cu}$ nanoparticles prepared from water solvent with $\mathbf{a} 0.04$ and $\mathbf{b} 0.20$ molar concentration of $\mathrm{CuSO}_{4}$ 
where $\beta_{\text {exp }}$ and $\beta_{\text {ins }}$ are the FWHM of experimental and instrumental profiles, respectively. $\beta_{\exp }$ and $\beta_{\text {ins }}$ were determined by Gaussian curve fitting using a Matlab software. The annealed copper with average grain size of $5 \mu \mathrm{m}$ was used as reference sample.

\section{Results and discussion}

\section{Effect of concentration of precursor}

Figure 1 shows the XRD patterns of the nanoparticles produced at various concentrations of precursor. For comparison, the XRD pattern of reference sample (annealed copper) has also been shown in this figure. Diffraction patterns are plotted by Gaussian curve fitting on data recorded by the APD 2000 X-ray diffractometer. It can be observed that the peaks of the reference sample were consistent with those of the standard JCPDS card No. 04-0836 for (111), (200), (220) and (311) planes of the pure face centered cubic (FCC) copper and no characteristic peaks of other phases have been recorded. The XRD patterns of the deposited specimens showed an additional peak, apart from the one which corresponds to metallic copper, appeared at $36.540-36.560$, matched with the standard JCPDS card No. 05-667 for (111) planes of body centered cubic (BCC) cuprite $\left(\mathrm{Cu}_{2} \mathrm{O}\right)$. The coexisting $\mathrm{Cu}_{2} \mathrm{O}$ is presumably due to some oxidation in air environment. The relative intensity of (111) planes of $\mathrm{Cu}_{2} \mathrm{O}$ for sample prepared form $0.04 \mathrm{M}$ solutions was considerably lower than that of 0.12 and $0.2 \mathrm{M}$ solutions, indicating the higher purity of obtained nanoparticles.

In Fig. 1, the peak broadening due to nano-sized crystallites is not completely clear. In order to have a better distinction between the samples, it is necessary that the intensity of (hkl) reflection, (Ihkl), be normalized in the form of IN, $\mathrm{hkl}=\mathrm{Ihkl} / \mathrm{Ip}$, hkl and IN, hkl be plotted versus diffraction angle, $(2 \theta)$ for the same reflection (Rashidi and Amadeh 2008). For this purpose, the intensity of (111) reflection of $\mathrm{Cu}$ for deposited specimens and also reference sample was normalized and presented in Fig. 2. As it can be seen, the XRD peaks of deposited samples are wider than the annealed copper and the peak width increases by decreasing the concentration of precursor. It should be noted that according to XRD theory, excess peak broadening (respect to annealed specimen) is due to crystallites refining to nanoscale size (Cullity 1978). From the peak broadening of XRD patterns, by means of a Scherrer relation fitting procedure, the values of the mean crystallites size have been determined for each sample. The evolution of the crystallites size of electroless deposited samples versus concentrations of $\mathrm{CuSO}_{4}$ in solution has been depicted in Fig. 3. It shows that a change of concentrations has a considerable effect on the crystallites refining of copper deposits. So increase in concentrations from 0.2 to $0.04 \mathrm{M}$ leads to decrease in copper crystallites size from $\sim 37$ to $\sim 22 \mathrm{~nm}$.

Through scanning electron microscopy (SEM) it was able to observe the morphology and particle size distribution of nanoparticles. In Fig. 4, typical SEM micrographs of the nanoparticles deposited from water solvent with 0.04 and 0.2 molar concentration (MC) of $\mathrm{CuSO}_{4}$ were presented. As shown in (Fig. 4a), the spherical and hemispherical nanoparticles with sizes of 10 to $110 \mathrm{~nm}$ are synthesized using a water solvent containing $0.04 \mathrm{M}$ copper sulfate. Figure $4 \mathrm{~b}$ shows strong agglomeration of nanoparticles with different

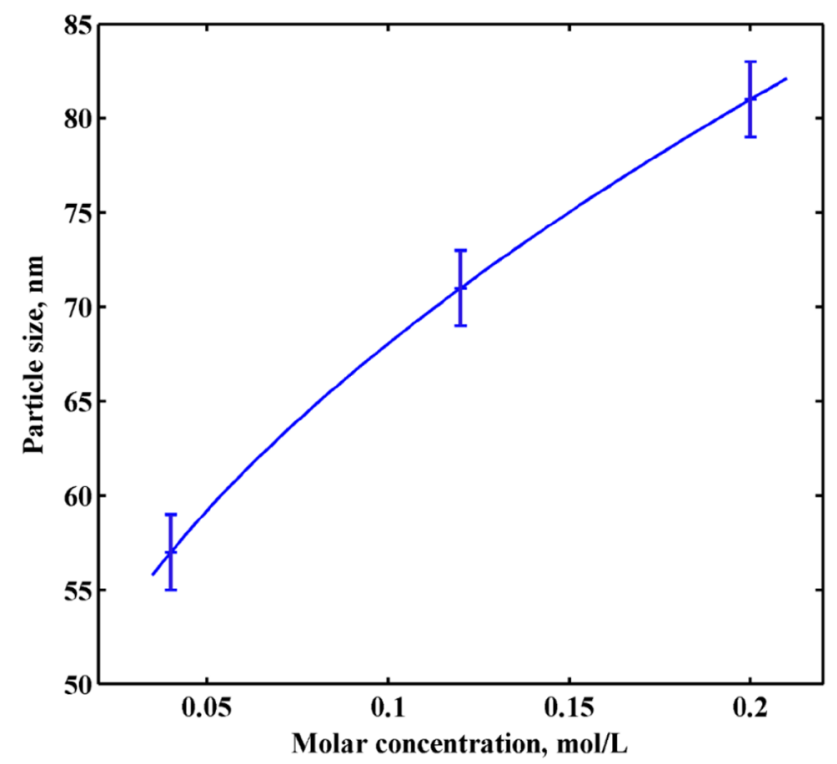

Fig. 6 Variation of average diameter of $\mathrm{Cu}$ nanoparticles as a function of $\mathrm{CuSO}_{4}$ concentration in water solvent

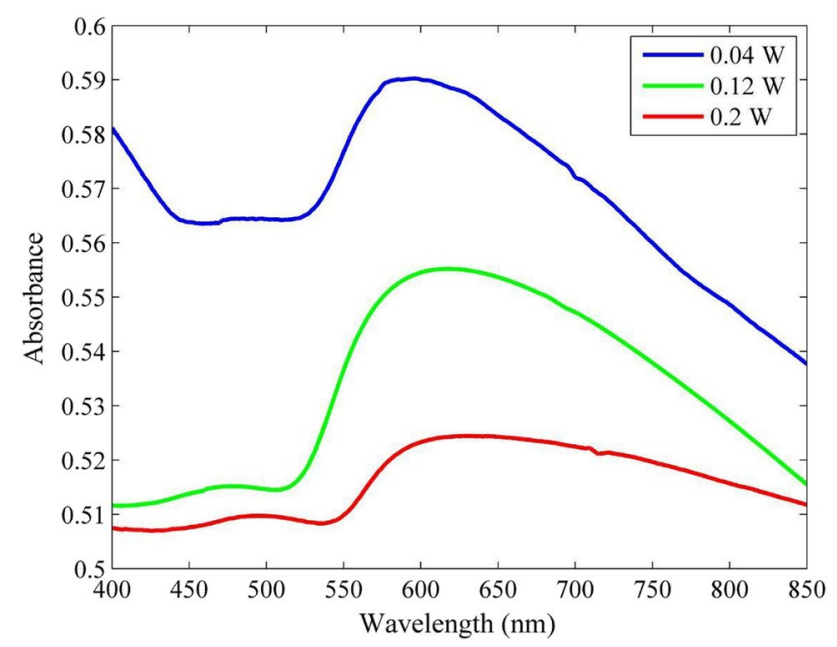

Fig. 7 UV-Vis absorption spectra of $\mathrm{Cu}$ nanoparticles formed in double distilled water with different concentration of $\mathrm{CuSO}_{4}$

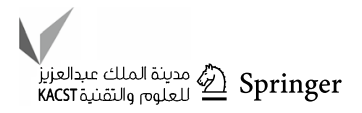


geometrical shapes, highlighting hemispherical particles with sizes of about 40 to $150 \mathrm{~nm}$ and a few rod-shaped particles with lengths of 150-200 nm. In addition, it was observed that these nanoparticles were overlapping with each other.

Particles size distribution and their mean diameter were analyzed by measuring over 100 particle dimensions from SEM images. The results are presented in Figs. 5 and 6. Accordingly, nanoparticles with an average diameter of

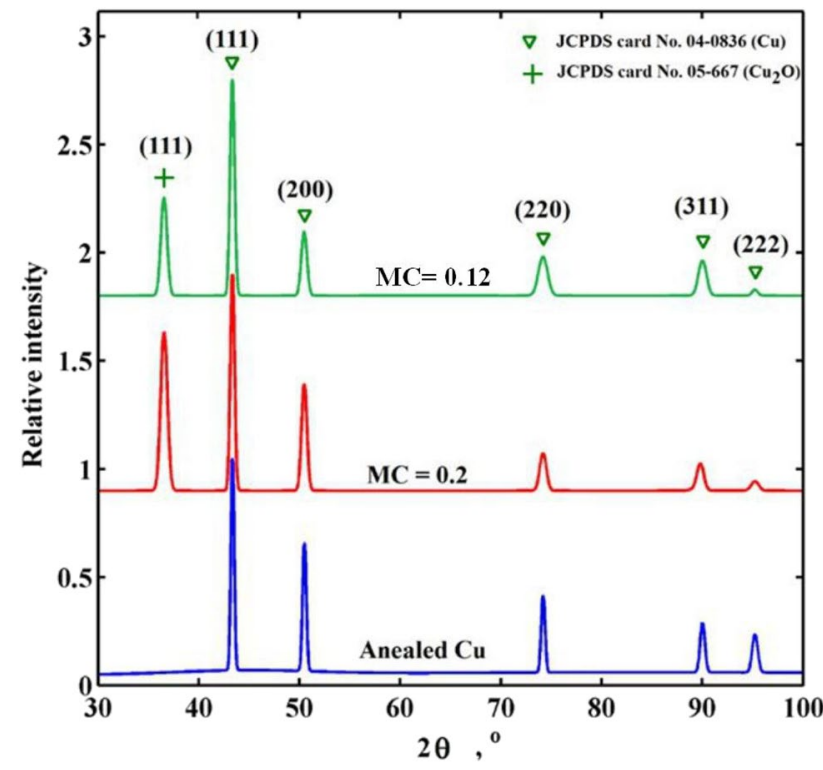

Fig. 8 XRD Pattern of nanoparticles prepared from ethylene glycol solvent with 0.12 and 0.2 molar concentration of $\mathrm{CuSO}_{4}$

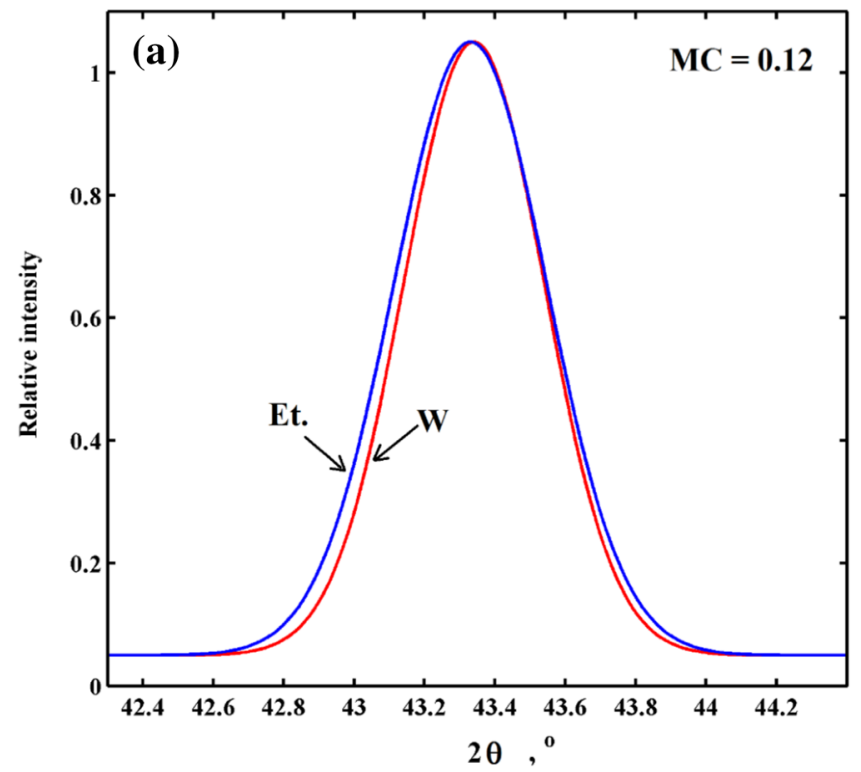

about $57 \pm 2 \mathrm{~nm}$ and a standard deviation (SD) of $16 \mathrm{~nm}$ were obtained using the $0.04 \mathrm{M}$ solution, whereas copper nanoparticles obtained from the $0.2 \mathrm{M}$ solution have an average diameter of about $81 \pm 2 \mathrm{~nm}$ with a standard deviation of $19 \mathrm{~nm}$. This means that the finer particles and better size distribution of $\mathrm{Cu}$ nanoparticles were achieved using a lower concentration of $\mathrm{CuSO}_{4}$.

Variation of average diameter of copper NPs as a function of $\mathrm{CuSO}_{4}$ concentration in distilled water solvent is presented in Fig. 6. It shows that the mean size of NPs grows by increasing the concentration of precursor. Contrary to the reported results by Kapoor and Mukherjee (Kapoor and Mukherjee 2003), the present results indicated that the mean of sizes, size distribution and morphology of copper NPs were affected by the concentration of $\mathrm{CuSO}_{4}$. This difference arises from difference in operating conditions. Kapoor and Mukherjee (Kapoor and Mukherjee 2003) used the photochemical method to fabrication nanoparticles copper from de-aerated aqueous solution of the $\mathrm{CuSO}_{4}$ in the presence of benzophenone and poly( $N$-vinylpyrrolidone) agents, whereas in this work, the copper NPs were synthesized via immersion plating method in aqueous solution of the $\mathrm{CuSO}_{4}$ without the use of any chemical stabilizer and protector agents.

The metal nanoparticles show broad regions of absorption in the UV-visible range due to the excitation of Surface Plasmon Resonances (SPR), which are specific properties for the metallic nature of particles, or interband transitions (Lotey et al. 2012 Mar 1). Totally, Cu nanoparticles have an SPR peak in the area nearly $600 \mathrm{~nm}$ (Dong et al. 2014). The

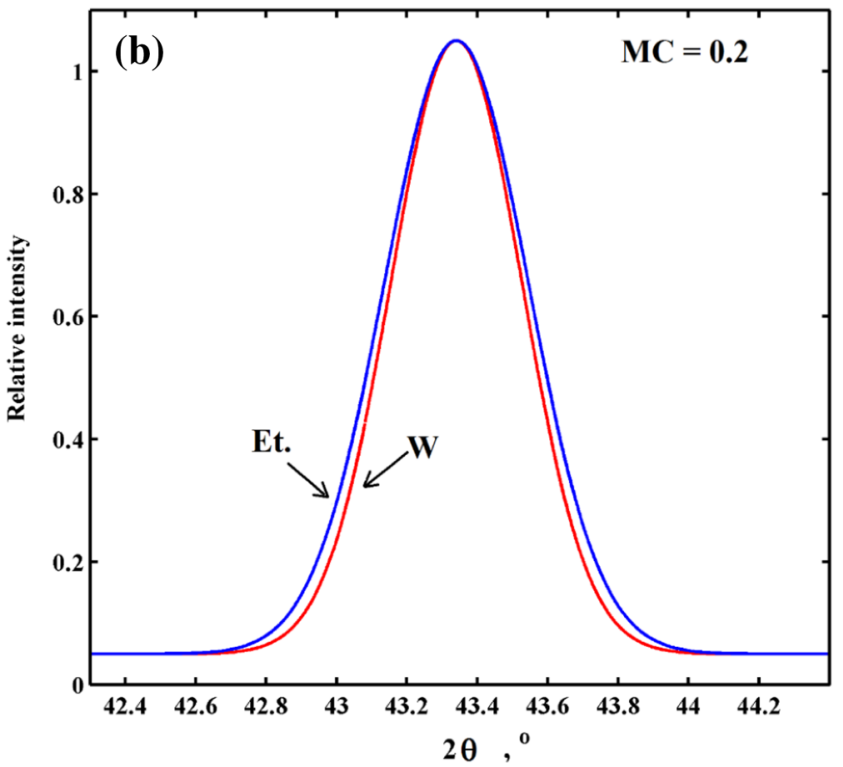

Fig. 9 Comparison of normalized (111) reflection peaks of $\mathrm{Cu}$ nanoparticles prepared from water (W) and ethylene glycol (Et) solvents with a 0.12 and b 0.2 molar concentration of $\mathrm{CuSO} 4$ 
UV-Vis absorption spectrum taken from the as-synthesized nanoparticles dispersed in aqueous solution with different concentration of $\mathrm{CuSO}_{4}$ are compared in Fig. 7. As it can be seen, the absorbance peaks of nanoparticles formed in distilled water with concentrations of $0.04,0.12$ and $0.2 \mathrm{M}$

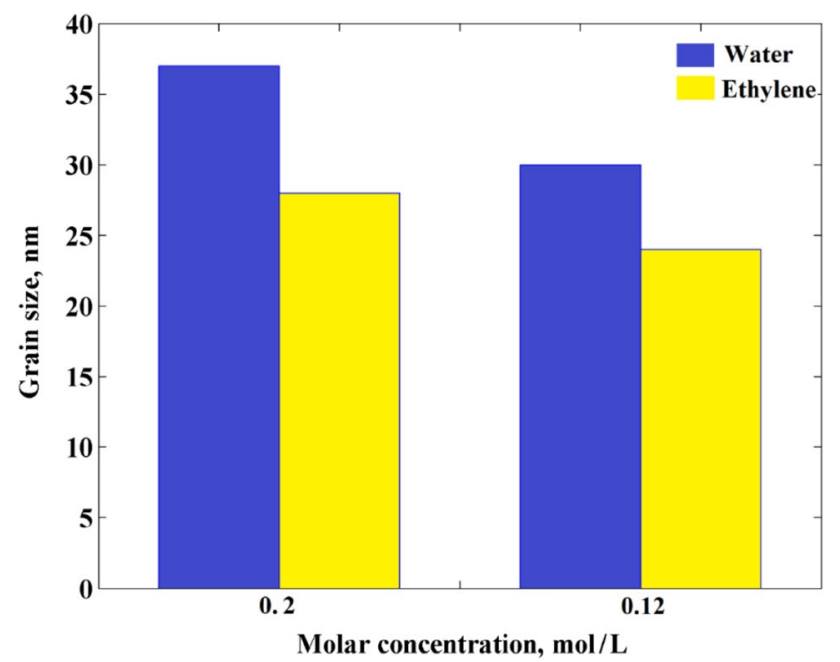

Fig. 10 Comparison of crystallite size of $\mathrm{Cu}$ nanoparticles prepared from water (W) and ethylene glycol (Et) solvents are revealed in 600, 617 and $630 \mathrm{~nm}$, respectively. These values are in good agreement with the reported results for copper nanoparticles (Dong et al. 2014). As the results show, the absorbance peak in $0.2 \mathrm{M}$ is weaker (broad peak with low intensity) than other concentrations.

This phenomena can be due to the formation of a thicker $\mathrm{Cu}_{2} \mathrm{O}$ layer (Ramyadevi et al. 2012; Khanna et al. 2008) and/ or wide distribution of particle sizes, intensive agglomeration and overlapping nanoparticles (Liu et al. 2002; Khanna et al. 2007).

A blue-shift is any decrease in wavelength with a corresponding increase in frequency of an electromagnetic wave. It is an indicator of decrease in size of particles and most clearly observed when the crystal sizes are close to the exciton radius in bulk semiconductor $(2-30 \mathrm{~nm})$. Figure 7 illustrates the blue shift appears when the concentration of $\mathrm{CuSO}_{4}$ in aqueous solution is reduced. This means that the finer nanoparticles can be synthesized using a solution with a lower concentration of $\mathrm{CuSO}_{4}$. The results are significantly compatible with the XRD results and SEM observations.

\section{Effect of solvent}

Figure 8 shows the XRD patterns of the nanoparticles produced from ethylene glycol solvent containing 0.12 and
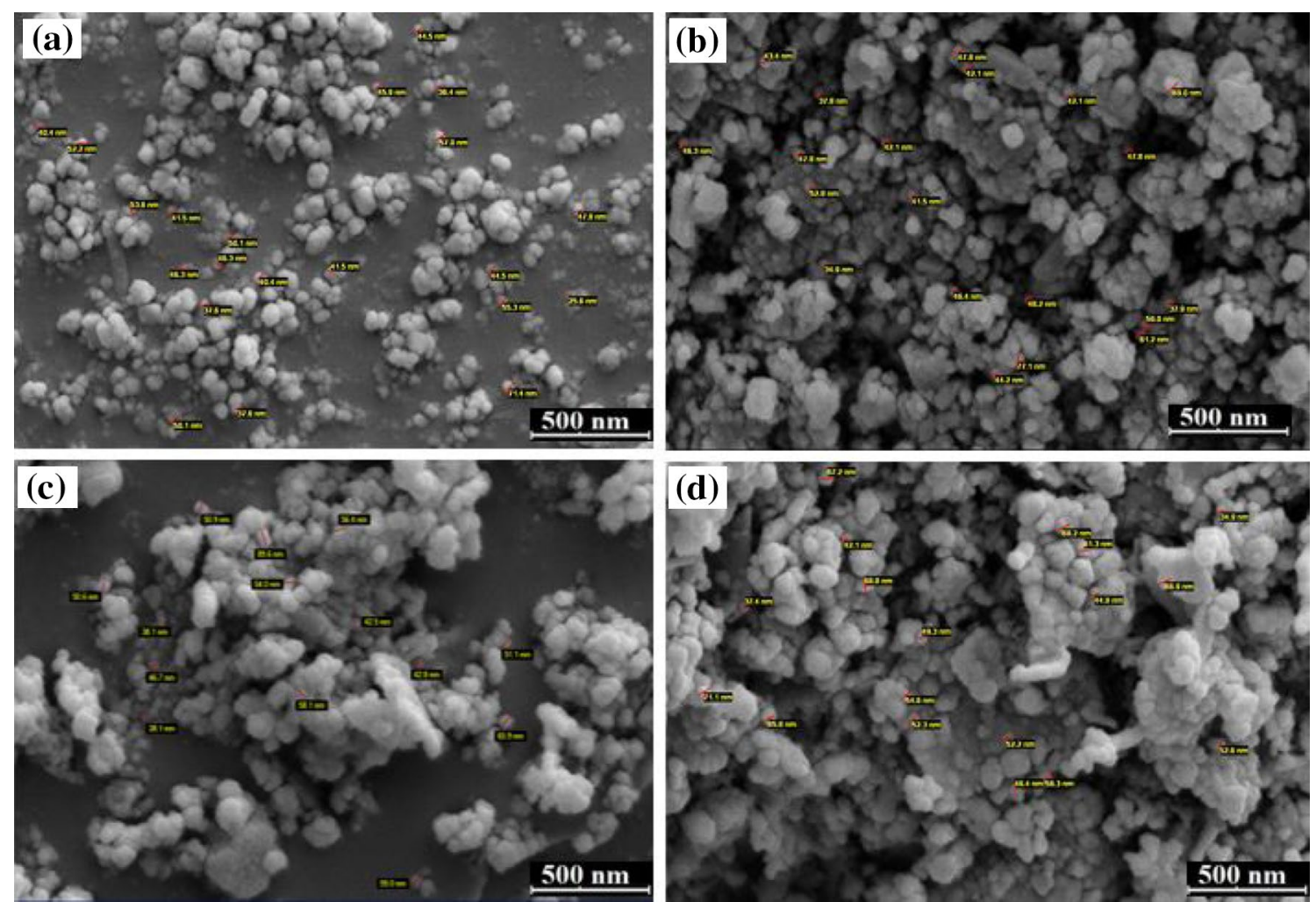

Fig. 11 SEM micrograph of $\mathrm{Cu}$ nanoparticles prepared from a $0.12 \mathrm{Et}, \mathbf{b} 0.12 \mathrm{~W}, \mathbf{c} 0.2 \mathrm{Et}$ and $\mathbf{d} 0.2 \mathrm{~W}$ molar concentration of $\mathrm{CuSO}_{4}$ 

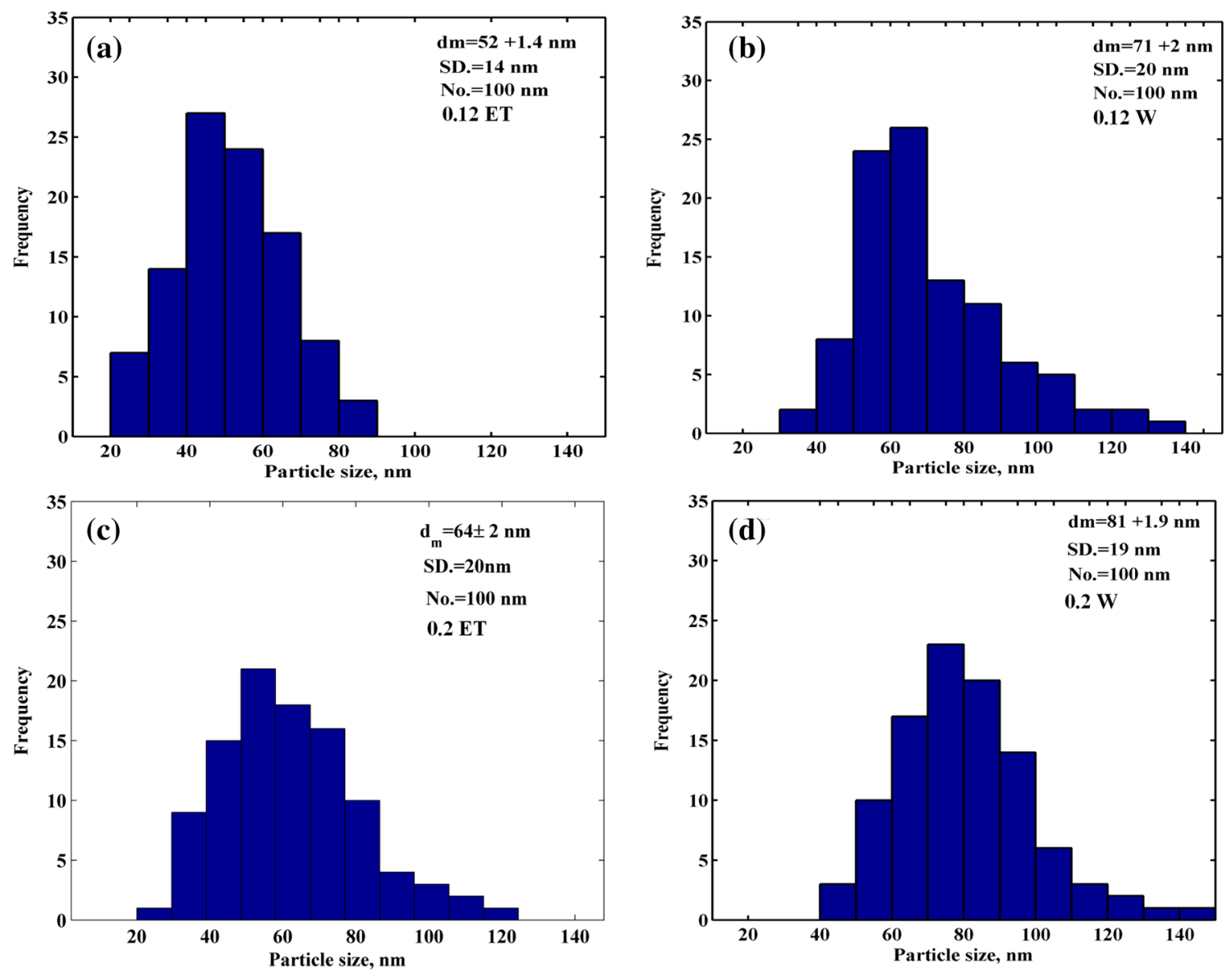

Fig. 12 Size histograms of $\mathrm{Cu}$ nanoparticles prepared from a $0.12 \mathrm{Et}, \mathbf{b} 0.12 \mathrm{~W}, \mathbf{c} 0.2 \mathrm{Et}$ and $\mathbf{d} 0.2 \mathrm{~W}$ molar concentration of $\mathrm{CuSO}_{4}$

$0.2 \mathrm{M}$ copper sulfate. The general form of XRD patterns is similar to Fig. 1. In order to have a better distinction between the XRD patterns of the nanoparticles produced from ethylene glycol and water solvents, the intensity of (111) reflection was normalized and compared in Fig. 9. As seen, the XRD peaks of nanoparticles produced from ethylene glycol solvent are wider than that of the water solvent. The values of the mean crystallites size determined from the intrinsic profile full width at half maximum intensity of (111) reflection are compared in Fig. 10. It shows that a change of solvent has an effect on the crystallites size of copper nanoparticles.

In Fig. 11, typical SEM micrographs of the nanoparticles deposited from water and ethylene glycol solvents with 0.12 and 0.2 molar concentration of $\mathrm{CuSO}_{4}$ are presented. As it can be seen, although the almost nanoparticles obtained from both solvents had spherical and semispherical morphology, however, the agglomeration and overlapping of nanoparticles in water were higher than that of ethylene glycol. The histograms of particles size distribution (Fig. 12) indicate that the nanoparticles with an average diameter of about $71 \pm 2 \mathrm{~nm}$ and $81 \pm 2 \mathrm{~nm}$ and a

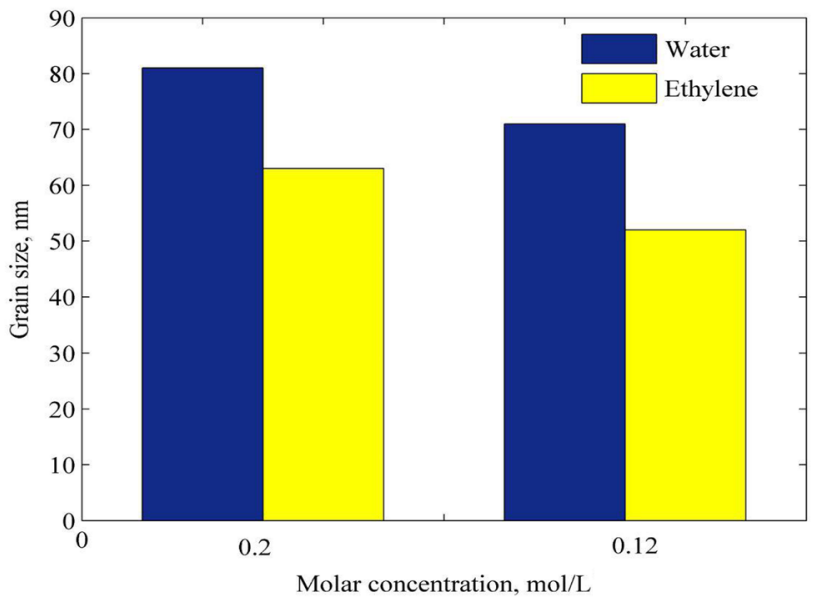

Fig. 13 Comparison of average diameter of $\mathrm{Cu}$ nanoparticles as a function of solvent

standard deviation of 20 and $19 \mathrm{~nm}$ are obtained using the $0.12 \mathrm{M}$ and $0.2 \mathrm{M}$ water solution, whereas average diameter of copper nanoparticles obtained from ethylene glycol was about of 52 and $64 \mathrm{~nm}$ with a standard deviation of 

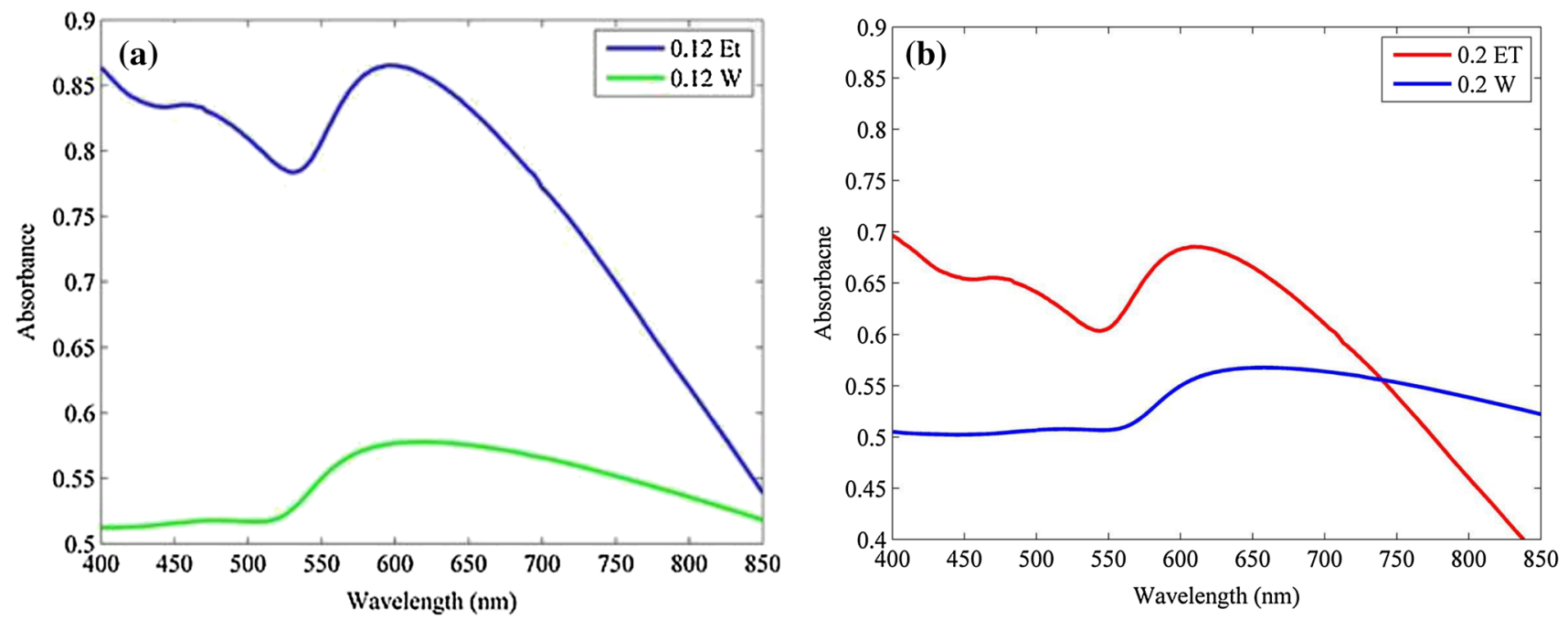

Fig. $14 \mathrm{UV}-$ Vis absorption spectra for ethylene glycol and water solvents with a 0.12 , b) 0.2 molar concentration of $\mathrm{CuSO}_{4}$

14 and $20 \mathrm{~nm}$. The values of the mean diameter obtained from the SEM measurement are compared in Fig. 13. As seen, the finer particles of $\mathrm{Cu}$ nanoparticles are obtained using ethylene glycol as a solvent.

In Fig. 14a and b, UV-Vis absorption spectra for water and ethylene glycol solvents in 0.12 and 0.2 molar concentration of $\mathrm{CuSO}_{4}$ are compared, respectively. As it can be seen, blue shift has occurred when changing solvent from distilled water to ethylene glycol. Also, band absorption is sharper due to decreasing particle size and overlapping and agglomeration narrower size distribution in ethylene glycol solvent. These results are in good agreement with the observation obtained from XRD and SEM.

\section{Conclusion}

In this research, the effects of copper sulfate concentrations and solvent type on the preparation of copper nanoparticles via immersion deposit method were experimentally investigated. The study demonstrated that the immersion deposit method is particularly suitable and generally applicable method for synthesis of copper nanoparticles. Based on the findings of the study the following conclusions were drawn.

Spherical and semispherical copper nanoparticles with the crystallites size from $\sim 22$ to $37 \mathrm{~nm}$ can be produced by immersion deposit method.

4.1 By increasing the molar concentration of copper sulfate in water solvent from 0.04 to $0.2 \mathrm{M}$, the average particles size of copper nanoparticle is increased from 57 to $81 \mathrm{~nm}$.
4.2 The better size distribution of $\mathrm{Cu}$ nanoparticles was achieved using a lower concentration of $\mathrm{CuSO}_{4}$.

4.3 It was obtained that the SPR peak position can be controlled during synthesis by varying the concentration of precursors and type of solvent, while the concentration of precursors increases from 0.04 to $0.2 \mathrm{M}$ in distilled water The SPR peak has red shift from 600 to $630 \mathrm{~nm}$ and this is related to reducing the particle size.

4.4 Blue shift and sharper peak were observed after changing the solvent water to ethylene glycol proving decrement of both size and distribution of them.

4.5 The finer $\mathrm{Cu}$ nanoparticles were formed using ethylene glycol instead of water as a solvent.

4.6 The agglomeration and overlapping of nanoparticles in ethylene glycol were less than that of water solvent.

\section{References}

Argueta-Figueroa L, Morales-Luckie RA, Scougall-Vilchis RJS, Olea-Mejía OF (2014) Synthesis, characterization and antibacterial activity of copper, nickel and bimetallic $\mathrm{Cu}-\mathrm{Ni}$ nanoparticles for potential use in dental materials. Prog Nat Sci 24(4):321-328

Barker BD (1981) Electroless deposition of metals. Surf Technol 12(1):77-88

Betancourt-Galindo R, Reyes-Rodriguez PY, Puente-Urbina BA, Avila-Orta CA, Rodríguez-Fernández OS, Cadenas-Pliego G, Lira-Saldivar RH, García-Cerda LA (2014) Synthesis of copper nanoparticles by thermal decomposition and their antimicrobial properties. J Nanomater 1(2014): 10

Camacho-Flores BA, Martínez-Álvarez O, Arenas-Arrocena MC, Garcia-Contreras R, Argueta-Figueroa L, de la Fuente-Hernández J, Acosta-Torres LS (2015) Copper: synthesis techniques in nanoscale and powerful application as an antimicrobial agent. $\mathrm{J}$ Nanomater 16(1):423 
Chatterjee AK, Chakraborty R, Basu T (2014) Mechanism of antibacterial activity of copper nanoparticles. Nanotechnology 25(13):135101

Cullity BD (1978) Answers to problems: elements of X-ray diffraction. Addison-Wesley Publishing Company, Boston

Dhas NA, Raj CP, Gedanken A (1998) Synthesis, characterization, and properties of metallic copper nanoparticles. Chem Mater 10(5):1446-1452

Dong C, Cai H, Zhang X, Cao C (2014) Synthesis and characterization of monodisperse copper nanoparticles using gum acacia. Phys $\mathrm{E}$ 31(57):12-20

Eastman JA, Choi SU, Li S, Yu W, Thompson LJ (2001) Anomalously increased effective thermal conductivities of ethylene glycolbased nanofluids containing copper nanoparticles. Appl Phys Lett 78(6):718-720

EmanAlzahrani, Ahmed RA (2016) Synthesis of copper nanoparticles with various sizes and shapes: application as a superior nonenzymatic sensor and antibacterial agent. Int J Electrochem Sci 11(6):4712-4723

Garg J, Poudel B, Chiesa M, Gordon JB, Ma JJ, Wang JB, Ren ZF, Kang YT, Ohtani H, Nanda J, McKinley GH (2008) Enhanced thermal conductivity and viscosity of copper nanoparticles in ethylene glycol nanofluid. J Appl Phys 103(7):074301

Hashemipour H, Zadeh ME, Pourakbari R, Rahimi P (2011) Investigation on synthesis and size control of copper nanoparticle via electrochemical and chemical reduction method. Int J Phys Sci 6(18):4331-4336

Henry JR (2001) Electroless (autocatalytic) plating. Met Finish 1(99):424-435

Huang HH, Yan FQ, Kek YM, Chew CH, Xu GQ, Ji W, Oh PS, Tang SH (1997) Synthesis, characterization, and nonlinear optical properties of copper nanoparticles. Langmuir 13(2):172-175

Kapoor S, Mukherjee T (2003) Photochemical formation of copper nanoparticles in poly (N-vinylpyrrolidone). Chem Phys Lett 370(1):83-87

Khan A, Rashid A, Younas R, Chong R (2016) A chemical reduction approach to the synthesis of copper nanoparticles. Int Nano Lett 6(1):21-26

Khanna PK, Gaikwad S, Adhyapak PV, Singh N, Marimuthu R (2007) Synthesis and characterization of copper nanoparticles. Mater Lett 61(25):4711-4714

Khanna PK, Kale TS, Shaikh M, Rao NK, Satyanarayana CV (2008) Synthesis of oleic acid capped copper nano-particles via reduction of copper salt by SFS. Mater Chem Phys 110(1):21-25

Kumar RV, Mastai Y, Diamant Y, Gedanken A (2001) Sonochemical synthesis of amorphous $\mathrm{Cu}$ and nanocrystalline $\mathrm{Cu}_{2} \mathrm{O}$ embedded in a polyaniline matrix. J Mater Chem 11(4):1209-1213

Lee Y, Choi JR, Lee KJ, Stott NE, Kim D (2008) Large-scale synthesis of copper nanoparticles by chemically controlled reduction for applications of inkjet-printed electronics. Nanotechnology 19(41):415604

Leong MK (2016) Green synthesis, characterization of copper (II) oxide nanoparticles and their photocatalytic activity (Doctoral dissertation, UTAR)

Liu X, Cai W, Bi H (2002) Optical absorption of copper nanoparticles dispersed within pores of monolithic mesoporous silica. J Mater Res 17(05):1125-1128

Lotey GS, Kumar S, Verma NK (2012) Fabrication and electrical characterization of highly ordered copper nanowires. Appl Nanosci 2(1):7-13

Magdassi S, Grouchko M, Kamyshny A (2010) Copper nanoparticles for printed electronics: routes towards achieving oxidation stability. Materials 3(9):4626-4638
Ohno I (1991) Electrochemistry of electroless plating. Mater Sci Eng A 146(1-2):33-49

Park BK, Jeong S, Kim D, Moon J, Lim S, Kim JS (2007) Synthesis and size control of monodisperse copper nanoparticles by polyol method. J Colloid Interface Sci 311(2):417-424

Porter LA, Choi HC, Ribbe AE, Buriak JM (2002) Controlled electroless deposition of noble metal nanoparticle films on germanium surfaces. Nano Lett 2(10):1067-1071

Qi L, Ma J, Shen J (1997) Synthesis of copper nanoparticles in nonionic water-in-oil microemulsions. J Colloid Interface Sci 186(2):498-500

Ramyadevi J, Jeyasubramanian K, Marikani A, Rajakumar G, Rahuman AA (2012) Synthesis and antimicrobial activity of copper nanoparticles. Mater Lett 15(71):114-116

Rashidi AM, Amadeh A (2008) The effect of current density on the grain size of electrodeposited nanocrystalline nickel coatings. Surf Coat Technol 202(16):3772-3776

Sáez V, Mason TJ (2009) Sonoelectrochemical synthesis of nanoparticles. Molecules 14(10):4284-4299

Schlesinger JM, Paunovic M (2010) Modern electroplating, vol 100, 5th edn. Wiley, Hoboken, pp 409-420

Sherazi ST, Soomro RA, Uddin S, Memon N (2014) Synthesis and characterizations of highly efficient copper nanoparticles and their use in ultra-fast catalytic degradation of organic dyes. Adv Mater Res 829:93-99

Shikha JA, Ankita JA, Kachhawah P, Devra V (2015) Synthesis and size control of copper nanoparticles and their catalytic application. Trans Nonferrous Met Soc China 25(12):3995-4000

Srinivasan KN, Shanmugam NV, Selvam M (1988) Immersion copper coating of steel. Bull Electrochem 4(04):315-317

Sudagar J, Lian J, Sha W (2013) Electroless nickel, alloy, composite and nano coatings-a critical review. J Alloy Compd 15(571):183-204

Tjong SC, Chen H (2004) Nanocrystalline materials and coatings. Mater Sci Eng 45(1):1-88

Umer A, Naveed S, Ramzan N, Rafique MS, Imran M (2014) A green method for the synthesis of Copper Nanoparticles using L-ascorbic acid. Matéria (Rio de Janeiro) 19(3):197-203

Usman MS (2013) Synthesis, characterization, and antimicrobial properties of copper nanoparticles. Int J Nanomed 8:4467-4479

Vitulli G, Bernini M, Bertozzi S, Pitzalis E, Salvadori P, Coluccia S, Martra G (2002) Nanoscale copper particles derived from solvated $\mathrm{Cu}$ atoms in the activation of molecular oxygen. Chem Mater 14(3):1183-1186

Xue J, Wu Q, Wang Z, Yi S (2006) Function of additives in electrolytic preparation of copper powder. Hydrometallurgy 82(3):154-156

Yagi S, Nakanishi H, Kawamori M, Donnabelle BM, Ichitsubo T, Matsubara E (2009) Electrochemical consideration of the synthesis of nanoparticles by electroless deposition. In Meeting Abstracts 2009 (No. 2, pp 119-119). The Electrochemical Society

Yli-Pentti A (2014) Electroplating and electroless plating. Compr Mater Process 198(4):277-306

Zhou R, Wu X, Hao X, Zhou F, Li H, Rao W (2008) Influences of surfactants on the preparation of copper nanoparticles by electron beam irradiation. Nucl Instrum Methods Phys Res Sect B 266(4):599-603

Publisher's Note Springer Nature remains neutral with regard to jurisdictional claims in published maps and institutional affiliations. 